\title{
Impact of Physical Activity Practice and Adherence to the Mediterranean Diet in Relation to Multiple Intelligences among University Students
}

\author{
José Luis Ubago-Jiménez ${ }^{1}{ }^{\mathbb{D}}$, Félix Zurita-Ortega ${ }^{1}{ }^{\mathbb{D}}$, Silvia San Román-Mata ${ }^{2, * \mathbb{C}}$, \\ Pilar Puertas-Molero ${ }^{1}$ and Gabriel González-Valero ${ }^{1}$ (D) \\ 1 Department of Musical, Plastic and Corporal Expression, University of Granada, 18071 Granada, Spain; \\ jlubago@ugr.es (J.L.U.-J.); felixzo@ugr.es (F.Z.-O.); pilarpuertas@correo.ugr.es (P.P.-M.); \\ ggvalero@ugr.es (G.G.-V.) \\ 2 Department of Nursing, University of Granada, 18071 Granada, Spain \\ * Correspondence: silviasanroman@ugr.es; Tel.: +34-958-246-685
}

Received: 11 August 2020; Accepted: 27 August 2020; Published: 28 August 2020

\begin{abstract}
Physical activity is important at any time of life. Particularly in the university, people tend to have more sedentary life, due to their studies. Eating habits are another health factor to consider. In addition, the Multiple Intelligences theory is a proposal that seeks the integral development and well-being of people. A descriptive, cross-sectional, and non-experimental research with the purpose of this study is to establish the relationships between practice of physical activity and the intelligences and determine the relationship between diet and the different types of intelligence in 215 university students. Findings indicate higher adherence to Mediterranean Diet in women and higher physical activity scores in men. Regarding multiple intelligences, men have higher indices in Bodily-kinesthetic, Interpersonal, Logical-mathematical, Musical, and Spatial intelligences, while women show higher levels in relation to Linguistic, Intrapersonal, and Naturalistic intelligences. Main conclusions from this study suggest the relationship between multiple intelligence and healthy habits, while also highlighting the need to improve eating habits and achieve greater adherence to Mediterranean Diet.
\end{abstract}

Keywords: multiple intelligence; Mediterranean diet; physical activity; university students

\section{Introduction}

The university stage is replete of numerous changes at the personal, social, and academic levels [1,2]. Likewise, all people have different skills and abilities. The concept about development of intelligence/skills as essential to accompany human beings throughout their lives has changed. Therefore, intelligences are understood as biological abilities, requiring the development of specific brain areas, which rarely work themselves [3,4]. This new tendency makes it possible to overcome the paradigm that placed learning based on exclusively genetic components, with the intelligence quotient (IQ) as the principal indicator. Consequently, it is necessary to attend personal and developmental needs in a customized form, because each individual to a greater or lesser extent developed type of intelligence $[5,6]$. Therefore, recognizing the student according to their capacities and strengths becomes an essential need for teaching at all educational levels.

The multiple intelligences (MI) theory shows how all people have a specific skill and a type of intelligence to a greater or lesser extent [7]. However, there are eight different intelligences with a specific location in the brain [8]. Focusing on the eight examples of knowledge, they are defined as:

- Naturalistic: The skill to recognize the order in nature and to organize and categorize the natural world. 
- Bodily-kinesthetic: Ability to express and solve problems through the body.

- Linguistic: Ability to use words and language effectively, and sensitivity to writing and communication.

- Logical-mathematical: High aptitudes for the use of numbers in an effective way, to recognize abstract patterns, to decipher relations, and of reasoning.

- Spatial: Ability to visualize and remember objects and spatial dimensions and to recreate mental images and illustrations.

- Musical: Ability to recognize tonal patterns and sounds, as well as sensitivity to rhythms.

- Interpersonal: Ability to understand people's moods, feelings, motivations, and intentions, as well as the leadership of groups of people.

- Intrapersonal: Ability to know oneself, reflect, and practice self-discipline.

This theory explains how each intelligence is developed in those activities which belong to them. Intelligence acquisition depends on cultural and environmental factors. Likewise, these abilities are related to individuals' experience and knowledge. Therefore, it can be trained [5,9].

Likewise, in the university stage, many eating habits are set aside, and ultra-processed products are consumed more frequently $[10,11]$. This factor of change makes it necessary to have a varied diet in foods such as the Mediterranean. It provides an improvement in living habits and provides the necessary nutrients $[12,13]$. The Mediterranean diet (MD) is rich in vegetables, fruits, legumes, nuts, and cereals, with olive oil as the basic dietary fat [14]. In this regard, MD is high in antioxidants, fibers, and polyunsaturated fats that reduce risk of different types of cancer [15]. The particularities of the MD not only include a wide variety of foods, but also a certain amount and consumption of these foods is recommended. However, particular emphasis is placed on the importance of food preparation [16,17]. In recent years, the proliferation of research pointing to and detecting the benefits of the nutritional components inherent in the MD on the contribution to health benefits, which are related to an increase in life expectancy, a decrease in the risk of suffering from cardiovascular disease, diabetes, infections, or cancer $[18,19]$.

Moreover, maintaining a good diet such as MD has positive effects on brain development and thus on intelligence [20,21]. In parallel, MD has been studied for its multiple benefits against cognitive impairment [22,23]. Numerous studies point out how MD foods, rich in omega-3s, support brain development $[24,25]$. Another factor that has a direct impact on the development of intelligence is the practice of physical activity (PA) [26]. When people practice sport, their organism produces a variety of neurotransmitters such as dopamine, serotonin, or norepinephrine which, among other factors, improve cognitive performance $[27,28]$. In addition, university students are often required to spend long periods of time in a sedentary environment in order to cope with their studies [29]. Consequently, it is necessary to develop adherence to physical activity to assist them in concentration [30], intellectual development [31,32], and cardiovascular health improvement [33].

Recent research suggests that different types of exercise promote cognitive function through neurobiology [34-36]. Aerobic training and resistance training impact the brain. Both influence the activation of the functional cortex [37] and increase the volume of the hippocampus [30]. The potential of this research is to unify the factors described, i.e., MI, MD, and PA, with the intention of examining the relationships between them and providing a university student profile by gender, based on the scores obtained on the instruments administered. Specifically, according to previous studies, within the theory defined by Gardner, special emphasis will be placed on bodily-kinesthetic intelligence, as it is intimately related to physical activity [38].

Accordingly, three hypotheses emerged in the present study. The first one assumes that "there are differences between MD, MI, and PA according to gender in favor to males". Secondly, we consider that there is a relationship between diet and MI. Specifically, we argue that "education students who have an optimal diet tend to have higher levels of bodily-kinesthetic intelligence". We also consider that there exists a relationship between PA and MI. In this regard, the third hypothesis of this study is "students who practice PA more often tend to have higher levels of MI". 
Taking into account the research questions defined above, the present research was designed with the following general aims: (a) Assess the intensity of individual dimensions of MI and the degree of implementation of the MD and the level of PA in undergraduates; and (b) analyze the relationship between MD, PA, and MI depending on gender.

\section{Materials and Methods}

\subsection{Subjects and Design}

This descriptive, cross-sectional, and non-experimental research project was carried out using a sample of 215 students who attended between the first and fourth year of their degree in the University of Granada (Granada, Spain), with a homogeneous distribution according to sex, representing 59.1\% $(n=127)$ females and $40.9 \%(n=88)$ males. Convenience sampling was used to recruit the participants. The age of the participants was between 18 and 48 years old $(21.12 \pm 4.34)$. It should be noted that 15 questionnaires were invalidated because they were not properly completed.

\subsection{Instruments}

Three different types of instrument were used in this research project. The first was an ad hoc questionnaire where undergraduates indicated their sex, their age, and academic year they were in.

In addition, in order to measure the level of physical activity exercised, questions were included in the ad hoc questionnaire regarding the time in minutes of moderate or intense physical activity performed each week and their relative personal capacity. Participants answered according to a Likert scale ranging from 0 (no physical activity or sport) to 10 (above their capacity). Core scores of 5 or 6 equaled moderate physical activity. Once these data were collected, the recommendations for physical activity made by the World Health Organization were taken into account [20]. Thus, the categories were whether people met minimum or active levels (HPA $>150 \mathrm{~min}$ of moderate physical activity) and did not meet minimum or sedentary levels (SPA $<150 \mathrm{~min}$ of moderate physical activity). The physically active category was defined as $\geq 150$ min per week of physical activity.

Adherence to the MD was assessed using the Mediterranean Diet Quality Index for children and adolescents (KIDMED) questionnaire [39], which contains 16 questions to be answered in a positive or negative way (yes/no). Affirmative answers in questions representing a negative connotation in relation to the Mediterranean diet are worth -1 point and positive answers in questions representing a positive connotation in relation to the Mediterranean diet are worth +1 point. Negative answers do not score. To represent what type of adherence each subject showed, values were assigned to each term as follows: Values between 8 and 12 (both included) were defined as an optimal diet, values between 4 and 7 were understood as an improbable diet, and values between -4 and 3 were understood as a low-quality diet.

The Multiple Intelligence Survey (MIS) [40] was used. The questionnaire is formed by 3 blocks of 9 items measuring each of the 8 intelligences: Linguistic (L); Logical-mathematical (LM); Bodily-kinesthetic (BK); Musical (M); Naturalistic (N); Spatial (S); Interpersonal (INTER); Intrapersonal (INTRA). Possible scores range from 3 to 27 with a midpoint of 15 . Participants have to rank all items starting with 1 for the item the most like them to 9 for the item least like them.

\subsection{Procedure}

Firstly, the Faculty of Education of the University of Granada (Granada, Spain) gave permission to researchers (1478/CEIH/2020). Afterwards, a document was drafted explaining the study nature and aims and requesting the consent of students who would like to participate. Once an affirmative response was received, the questionnaire was sent by email so that participants could respond honestly. A total of 230 students took part in this project, and 15 questionnaires were invalidated because they were not correctly completed. The instruments were applied from February to March 2019. Anonymity and confidentiality of the data were ensured. Data were collected and their quality was confirmed, 
whilst ensuring throughout that the process conformed to the ethical principles for research defined in the Helsinki's Declaration in 1975 and subsequently updated in Brazil in 2013.

\subsection{Statistical Analysis}

For data analysis, the statistical software IBM SPSS 25.0. (International Business Machines Corporation, Armonk, NY, USA) was used in order to establish the values of the basic descriptors (means and frequencies). The magnitude of the differences or effect size was determined using Cohen's standardized measure $d$, and was interpreted as zero (0-0.19), low (0.20-0.49), moderate (0.50-0.79), or high $(\geq 0.80)$. Therefore, for each effect size, the $95 \%$ confidence interval (95\% CI) was calculated. In order to understand differences between two correlations, the effect size was calculated with Cohen's q. Both correlations were converted to Fisher's $\mathrm{Z}$ and subtracted from each other. This measure can be interpreted as: $\leq 0.1$ (no effect), 0.1-0.3 (small effect), 0.3-0.5 (medium effect), and $\geq 0.5$ (large effect). On the other hand, the differences between categorical variables were determined through contingency tables. Likewise, the differences between variables of categorical and interval type were analyzed using ANOVA and a Student's t-test. Likewise, the Bonferroni test was applied to verify inter-group differences. We also performed linear regression analysis to study the association between adherence to MD and PA (independent variables) and MI (dependent variable), adjusted for gender.

\section{Results}

The results achieved in the present investigation variables are shown in Table 1 in relation to participants' gender. A statistically significant relation was found in four of the eight intelligence categories, as well as in adherence to the MD and PA practice $(p<0.05)$. For BK intelligence, women showed higher average values $(17.16 \pm 6.23)$ than men $(16.01 \pm 7.06)(p=0.022)$. There were also higher average values for females in the INTER, $M$, and $S$ intelligences $(16.46 \pm 5.62 ; 17.17 \pm 5.76$; $16.06 \pm 5.33)$, respectively $(p=0.028 ; p=0.020 ; p=0.031)$, than males $(15.80 \pm 7.06 ; 15.35 \pm 5.20$; $14.83 \pm 4.95)$, respectively. At a significant level of $p<0.001$, it was noted that women have higher average levels in KIDMED than men $(8.86 \pm 2.46$ vs. $6.75 \pm 2.48)$. However, males have higher average in PA $(4.07 \pm 0.52)$ than females $(3.86 \pm 0.49)$. In addition, there were also statistically significant differences $p=0.030$ between women and men who perform HPA. In contrast, there were also statistically significant differences in terms of SPA $(p<0.001)$, where men have a higher average than women.

Table 1. Multiple intelligence, Mediterranean diet, and physical activity practice according to the participants' gender.

\begin{tabular}{|c|c|c|c|c|c|c|c|c|c|}
\hline \multirow{2}{*}{ Variable } & \multicolumn{2}{|c|}{ Male } & \multicolumn{2}{|c|}{ Female } & \multicolumn{2}{|c|}{ Levene Test } & \multirow{2}{*}{ Sig. (Bilateral) } & \multirow{2}{*}{ ES (d) } & \multirow{2}{*}{$95 \% \mathrm{CI}$} \\
\hline & $\mathbf{M}$ & S.D. & $\mathbf{M}$ & S.D. & $\mathbf{F}$ & Sig. & & & \\
\hline BK & 16.01 & 7.06 & 17.16 & 6.23 & 6.29 & 0.01 & 0.022 * & 0.161 & $(-0.111 ; 0.433)$ \\
\hline INTER & 15.80 & 5.99 & 16.46 & 5.62 & 16.74 & 0.00 & $0.028 *$ & 0.114 & $(-0.158 ; 0.386)$ \\
\hline INTRA & 17.69 & 6.17 & 16.92 & 6.63 & 2.57 & 0.11 & 0.173 & 0.119 & $(-0.153 ; 0.392)$ \\
\hline $\mathbf{L M}$ & 15.26 & 5.76 & 16.88 & 5.79 & 3.03 & 0.08 & 0.921 & 0.281 & $(0.007 ; 0.553)$ \\
\hline $\mathbf{M}$ & 15.35 & 5.20 & 17.17 & 5.76 & 0.17 & 0.67 & $0.020 *$ & 0.328 & $(0.055 ; 0.602)$ \\
\hline $\mathbf{N}$ & 16.89 & 6.06 & 15.90 & 6.47 & 3.90 & 0.04 & 0.544 & 0.157 & $(-0.115 ; 0.429)$ \\
\hline $\mathbf{L}$ & 14.49 & 5.54 & 14.05 & 5.89 & 0.01 & 0.89 & 0.754 & 0.076 & $(-0.196 ; 0.348)$ \\
\hline $\mathbf{S}$ & 14.83 & 4.95 & 16.06 & 5.33 & 0.39 & 0.53 & $0.031 *$ & 0.237 & $(-0.035 ; 0.510)$ \\
\hline KIDMED & 6.75 & 2.48 & 8.86 & 2.46 & 6.39 & 0.00 & $0.000 *$ & 0.853 & $(0.853 ; 1.136)$ \\
\hline PA & 4.07 & 0.52 & 3.86 & 0.49 & 3.17 & 0.65 & $0.000 *$ & 0.413 & $(0.139 ; 0.688)$ \\
\hline HPA & 3.92 & 1.02 & 3.24 & 0.81 & 0.04 & 0.82 & $0.030 *$ & 0.312 & $(0.141 ; 0.424)$ \\
\hline SPA & 2.46 & 0.67 & 2.20 & 0.74 & 0.01 & 0.91 & $0.000 *$ & 0.230 & $(0.241 ; 0.474)$ \\
\hline
\end{tabular}

Note: Effect size Cohen's d (ES); 95\% Confidence Interval (CI); Bodily-kinesthetic (BK); Interpersonal (INTER); Intrapersonal (INTRA); Logical-mathematical (LM); Musical (M); Naturalistic (N); Linguistic (L); Spatial (S); Mediterranean Diet Adherence (KIDMED); Physical Activity (PA); Physical Activity Healthy (PAH); Physical Activity Sedentary (PAS). ${ }^{*} p<0.05$

Table 2 shows the correlations between the different investigation variables in relation to the female. The strongest relationships were found among women who have developed LM and have 
greater skills in INTRA intelligence $(r=0.748)$, with BK intelligence $(r=0.669)$, with $S$ intelligence $(r=0.616)$, with $\mathrm{M}$ intelligence $(r=0.603)$, and with $\mathrm{N}$ intelligence $(r=0.585)$. On the other hand, the BK intelligence presented a strong correlation with the INTRA $(r=0.670)$, INTER $(r=0.633)$, $\mathrm{S}(r=0.573), \mathrm{M}(r=0.563)$, and $\mathrm{N}(r=0.539)$ intelligences. Likewise, for DM only correlations with INTER intelligence $(r=0.630)$ were found. Finally, for PA no correlation was found with any type of intelligence although a negative correlation was obtained with $\operatorname{MD}(r=-0.233)$.

Table 2. Bivariate correlations between multiple intelligences, PA, and MD for females.

\begin{tabular}{|c|c|c|c|c|c|c|c|c|c|c|}
\hline & BK & INTER & INTRA & LM & $\mathbf{M}$ & $\mathbf{N}$ & $\mathbf{L}$ & $S$ & MD & PA \\
\hline BK & & $0.633^{* *}$ & $0.670^{* *}$ & $0.669^{* *}$ & 0.563 ** & $0.539 * *$ & $0.375^{* *}$ & $0.573 * *$ & 0.033 & -0.142 \\
\hline INTER & & & $0.508^{* *}$ & $0.519^{* *}$ & $0.448^{* *}$ & $0.381^{* *}$ & 0.311 ** & $0.380^{* *}$ & 0.630 ** & -0.171 \\
\hline INTRA & & & & $0.748^{* *}$ & $0.665^{* *}$ & $0.649^{* *}$ & 0.396 ** & $0.670^{* *}$ & 0.008 & 0.002 \\
\hline LM & & & & & $0.603 * *$ & $0.585^{* *}$ & $0.491 * *$ & $0.616^{* *}$ & 0.020 & -0.068 \\
\hline $\mathbf{M}$ & & & & & & $0.539^{* *}$ & $0.436^{* *}$ & $0.573^{* *}$ & 0.016 & 0.078 \\
\hline $\mathbf{N}$ & & & & & & & $0.427^{* *}$ & $0.454^{* *}$ & -0.055 & -0.037 \\
\hline L & & & & & & & & $0.423^{* *}$ & 0.116 & -0.007 \\
\hline $\mathrm{S}$ & & & & & & & & & 0.083 & 0.012 \\
\hline MD & & & & & & & & & & $-0.233 * *$ \\
\hline PA & & & & & & & & & & \\
\hline
\end{tabular}

**: Correlation significant at 0.01 level (bilateral); *: Correlation significant at 0.05 level (bilateral); Physical Activity (PA); Bodily-kinesthetic (BK); Interpersonal (INTER); Intrapersonal (INTRA); Logical-mathematical (LM); Musical (M); Naturalistic (N); Linguistic (L); Spatial (S); Mediterranean Diet Adherence (MD).

Finally, correlation coefficients were shown between multiple intelligences, MD adherence, and PA for males (Table 3). In relation to MD, the most significant result was the positive correlation with BK $(r=0.245)$ and $\mathrm{N}(r=0.215)$, as well as establishing positive correlations with PA $(r=0.179)$. Based on PA, positive correlations were found with intelligence INTRA $(r=0.213)$. Among the different intelligences the strongest correlations were between the intelligence BK and INTER $(r=0.639)$, the M and the $\mathrm{N}(r=0.638)$, between the INTRA with the LM $(r=0.629)$, BK $(r=0.617)$, and the M $(r=0.602)$. Likewise, within the associations among the different intelligences, $\mathrm{M}$ shows a positive correlation with $\mathrm{S}(r=0.600)$; LM correlates positively with BK $(r=0.590), \mathrm{M}(r=0.580)$, and $\mathrm{S}(r=0.554)$. Likewise, for MD, correlations were found with the BK $(r=0.245)$ and $\mathrm{N}(r=0.215)$ intelligences. Correlations were found for PA with the INTRA intelligence $(r=0.213)$ and with MD $(r=0.179)$.

Table 3. Bivariate correlations between multiple intelligences, PA, and MD for males.

\begin{tabular}{|c|c|c|c|c|c|c|c|c|c|c|}
\hline & BK & INTER & INTRA & LM & $\mathbf{M}$ & $\mathbf{N}$ & L & $S$ & MD & PA \\
\hline BK & & 0.639 ** & $0.617^{* *}$ & $0.590 * *$ & 0.567 ** & $0.541^{* *}$ & $0.211^{*}$ & 0.464 ** & $0.245^{*}$ & -0.005 \\
\hline INTER & & & $0.516^{* *}$ & $0.415^{* *}$ & $0.566^{* *}$ & $0.504^{* *}$ & 0.120 & $0.469 * *$ & 0.124 & -0.102 \\
\hline INTRA & & & & $0.629 * *$ & $0.602 * *$ & $0.578 * *$ & $0.315^{* *}$ & $0.542 * *$ & 0.144 & $0.213 *$ \\
\hline $\mathbf{L M}$ & & & & & 0.580 ** & $0.419 * *$ & $0.356^{* *}$ & 0.554 ** & 0.166 & 0.114 \\
\hline $\mathbf{M}$ & & & & & & $0.638 * *$ & $0.415^{* *}$ & $0.600 * *$ & 0.063 & 0.027 \\
\hline $\mathbf{N}$ & & & & & & & $0.495 * *$ & $0.479 * *$ & $0.215 *$ & -0.047 \\
\hline $\mathbf{L}$ & & & & & & & & $0.466^{* *}$ & 0.182 & -0.042 \\
\hline $\mathbf{S}$ & & & & & & & & & 0.049 & 0.156 \\
\hline MD & & & & & & & & & & 0.179 * \\
\hline PA & & & & & & & & & & \\
\hline
\end{tabular}

**: Correlation significant at 0.01 level (bilateral); *: Correlation significant at 0.05 level (bilateral); Physical Activity (PA); Bodily-kinesthetic (BK); Interpersonal (INTER); Intrapersonal (INTRA); Logical-mathematical (LM); Musical (M); Naturalistic (N); Linguistic (L); Spatial (S); Mediterranean Diet Adherence (MD).

Linear regression analyses were performed to check the association between PA and MD for each of the eight intelligences. The regression was also carried out differentiating between men and women (Table 4). For the predictive models in relation to the male sex, only PA was a predictive variable of intelligence $\mathrm{BK}(\beta=0.157 ; p=0.015)$, which explains $39 \%$ of the variance of the response variable. On the other hand, in the case of women, MD was a predictive variable of INTER intelligence $(\beta=0.326 ; p=0.025)$, explaining $11 \%$ of the variance. For the rest of the intelligences none of the variables introduced were significant predictors. 
Table 4. Regression model for multiple intelligences, PA, and MD.

\begin{tabular}{|c|c|c|c|c|c|c|c|c|c|c|c|c|}
\hline \multirow{2}{*}{ Variables } & \multicolumn{2}{|c|}{ Standardized $\beta$} & \multicolumn{2}{|c|}{$t$} & \multicolumn{2}{|c|}{$p$} & \multicolumn{2}{|c|}{$95 \% \mathrm{CI}$} & \multicolumn{2}{|c|}{$\mathbf{R}^{2}$} & \multicolumn{2}{|c|}{ Adjusted $\mathrm{R}^{2}$} \\
\hline & Male & Female & Male & Female & Male & Female & Male & Female & Male & Female & Male & Female \\
\hline \multicolumn{13}{|c|}{ Bodily-Kinesthetic } \\
\hline PA & 0.157 & 0.144 & -1.571 & -1.428 & 0.015 & 0.098 & $(-4.05 ; 0.46)$ & $(-3.87 ; 0.35)$ & 0.402 & 0.114 & 0.397 & 0.094 \\
\hline MD & 0.134 & 0.430 & -0.343 & -0.341 & 0.118 & 0.215 & $(-1.74 ; 1.68)$ & $(-1.55 ; 1.22)$ & & & & \\
\hline \multicolumn{13}{|c|}{ Interpersonal } \\
\hline $\mathrm{PA}$ & 0.160 & 0.158 & -1.772 & -1.701 & 0.059 & 0.257 & $(-3.83 ; 0.21)$ & $(-3.64 ; 0.31)$ & 0.215 & 0.162 & 0.187 & 0.112 \\
\hline MD & 0.530 & 0.326 & 0.594 & 0.624 & 0.556 & 0.025 & $(-1.08 ; 1.98)$ & $(-1.14 ; 1.33)$ & & & & \\
\hline \multicolumn{13}{|c|}{ Intrapersonal } \\
\hline PA & 0.028 & 0.375 & 0.038 & 0.106 & 0.087 & 0.072 & $(-1.51 ; 1.58)$ & $(-1.28 ; 1.42)$ & 0.005 & 0.021 & 0.000 & 0.014 \\
\hline MD & 0.034 & 0.204 & 0.044 & 0.091 & 0.980 & 0.215 & $(-1.97 ; 0.73)$ & $(-1.84 ; 0.85)$ & & & & \\
\hline \multicolumn{13}{|c|}{ Logical-Mathematical } \\
\hline PA & 0.851 & 0.824 & -0.789 & -0.841 & 0.269 & 0.641 & $(-1.67 ; 0.59)$ & $(-1.74 ; 0.62)$ & 0.129 & 0.016 & 0.085 & 0.003 \\
\hline MD & 0.158 & 0.213 & -0.188 & -0.142 & 0.652 & 0.357 & $(-1.87 ; 1.52)$ & $(-1.48 ; 1.05)$ & & & & \\
\hline \multicolumn{13}{|l|}{ Musical } \\
\hline PA & 0.674 & 0.521 & 0.945 & 0.749 & 0.651 & 0.322 & $(-1.09 ; 3.11)$ & $(-1.12 ; 2.54)$ & 0.118 & 0.154 & 0.114 & 0.123 \\
\hline MD & 0.457 & 0.326 & 0.454 & 0.268 & 0.346 & 0.218 & $(-1.23 ; 1.97)$ & $(-1.08 ; 1.67)$ & & & & \\
\hline \multicolumn{13}{|l|}{ Naturalistic } \\
\hline PA & 0.840 & 0.754 & 0.595 & 0.678 & 0.063 & 0.478 & $(-2.87 ; 1.54)$ & $(-1.91 ; 1.23)$ & 0.184 & 0.218 & 0.175 & 0.137 \\
\hline MD & 0.544 & 0.564 & 0.922 & 0.523 & 0.358 & 0.235 & $(-2.46 ; 0.89)$ & $(-2.32 ; 1.43)$ & & & & \\
\hline \multicolumn{13}{|l|}{ Linguistic } \\
\hline PA & 0.264 & 0.185 & 0.186 & 0.286 & 0.853 & 0.677 & $(-1.82 ; 2.20)$ & $(-1.84 ; 2.01)$ & 0.113 & 0.167 & 0.097 & 0.094 \\
\hline MD & 0.115 & 0.174 & 1.263 & 0.727 & 0.209 & 0.258 & $(-0.55 ; 2.51)$ & $(-0.84 ; 1.88)$ & & & & \\
\hline \multicolumn{13}{|l|}{ Spatial } \\
\hline $\mathrm{PA}$ & 0.863 & 0.728 & 0.173 & -0.254 & 0.863 & 0.681 & $(-1.78 ; 2.12)$ & $(-1.66 ; 2.03)$ & 0.204 & 0.026 & 0.154 & 0.002 \\
\hline MD & 0.839 & 0.817 & 0.203 & -0.193 & 0.839 & 0.107 & $(-1.33 ; 1.63)$ & $(-1.42 ; 1.52)$ & & & & \\
\hline
\end{tabular}




\section{Discussion}

Maintaining a healthy lifestyle is associated with doing PA and adopting a healthy diet. Moreover, considering young people are involved in a life process requiring several changes in personal, physical, and psychological spheres, the main objective of this research was to identify the relationships between eating habits, PA practice, and MI in undergraduates. In addition, intelligence is also influenced when acquiring those habits. It also intends to establish conclusions to help understand the relationship between the different variables. Therefore, it is necessary to promote healthy habits $[12,17,41,42]$. Some studies of similar characteristics [43-45] have been conducted among undergraduates. However, no studies have been conducted associating healthy habits and MI.

In the first hypothesis of the present research, differences between variables considered according to gender existed. This hypothesis was partially confirmed. While we considered that men would score higher on all three variables, the talk obtained showed that men obtained higher PA scores than women. As for MI, similar scores were observed in relation to gender, although the highest score was obtained by women in M intelligence. Concerning MD, women obtained higher scores. Accordingly, findings suggested that undergraduates with moderate to high adherence to MD do regular exercise. Likewise, it showed how females, even though their diet levels are higher, had less PA practice than males. Similar findings can be observed in the study by Chacón-Cuberos et al. [46] showing how women have a better diet in relation to men. The current research shows how women adhere better to MD even though they have lower PA than men [47,48]. In contrast, similar studies [49,50] found a positive relationship between adherence to MD and PA with no differences observed between men and women.

In relation to the second hypothesis considering a relationship between having high levels of $\mathrm{MD}$ and $\mathrm{BK}$ intelligence, the hypothesis was confirmed in the case of men, along with the $\mathrm{N}$ one. For women, a relationship with INTER intelligence was found. Although there are no studies that connect adherence to MD with MI, there are studies that identify nutritional habits as contributing to better brain functioning and thus intelligence [51]. In addition, several studies have found significant positive effects on health from the ingestion of varied foods such as vegetables, fruits, fish, meat, or olive oil that constitute MD [52-55]. Findings obtained disagree with the study by Jackson and Beaver [51] who establish a relationship between healthy eating habits and verbal intelligence. MD is also positively linked to verbal intelligence in other studies [52].

For the analysis of third hypothesis of the present research, it was important to focus on the levels found for MI. Thus, the results shown in relation to multiple intelligences show how the findings were similar between men and women. It is important to highlight how male undergraduates showed higher levels in relation to BK, INTER, LM, M, and S intelligences. In contrast, females showed higher levels in relation to L, INTRA, and N. These results are similar to findings being obtained by Oh et al. [49] but they were different from the results obtained by Furnham and Shagabutdinova [50] and Chan [56]. These investigations show how women showed higher levels in INTRA, INTER, M, and L than men. These values are linked to PA, because BK intelligence and sports practice were higher in men. Moreover, it has been confirmed by several empirical researches [57-59]. However, those findings differ from the findings reported by Ermis and Imamoglu [57], which analyzed how exercise affects multiple intelligences. It was found in this study involving 1580 students that women scored higher levels in visual and musical intelligence and lower in intrapersonal intelligence than men.

Regarding the intensity of $\mathrm{PA}$, it was found that men present higher values than women in relation to HPA. Similar data are found in several studies carried out on university students [60-62]. Likewise, men obtained higher results than women in relation to SPA. These findings differ from the review by Panadero-Pérez et al. [63] among adolescents and young adults. It should also be noted that these findings offer a starting point for research into the impact of PA practice and maintaining a diverse diet full of food items such as MD. A further research direction is the establishment of an intervention based on the practice of PA, a quasi-experimental study, to measure the relationship and the more detailed influence between diet and PA on the development of intelligences among students. 
The present research also had some limitations. Firstly, it was carried out with undergraduates to ensure the sample was compared with similar studies. In addition, the study employed a descriptive and cross-sectional design providing useful information on this emerging topic but avoiding casual conclusions. Another limitation refers to the variables used, since although these are valid for fulfilling the study's aims, it would have been interesting to include others of great relevance such as the body mass index or total daily energy intake. The MIS questionnaire is also another limitation, since it evaluates a person's self-knowledge of their own tastes, so it would be interesting to introduce a questionnaire that measures intelligence objectively. This would make it possible to further investigations the relationship between MI, eating habits, and health status. However, the strength of the correlations was generally low, even though significant relationships were developed for MD, PA, and MI. Recognizing the above limitations, we make the following suggestions for future research. This study should be replicated and expanded with other samples and exploring other variables, such as psychosocial factors or emotional intelligence. In addition, it would be interesting to develop an intervention program to check out the combined influence of MD and PA on the development of MI and the academic performance of undergraduates.

\section{Conclusions}

The main conclusions of this research show the importance of improving dietary habits and achieving greater adherence to $\mathrm{MD}$, with a special emphasis on consumption of fruits, vegetables, fish, cereals, and nuts. In addition, various intelligences were positively associated with these healthy habits. Based on the initial hypotheses, it was corroborated that women undergraduates show better eating habits and men show a higher rate of physical activity. It is necessary to promote healthy habits, as physical and cognitive benefits are achieved in time. Adhering to a specific program of MD and regularly exercise could improve different intelligences of further professionals. These findings support the need to promote physical activity and provide basic nutritional education to improve people's quality of life. Furthermore, the relationships found between some of the intelligences included in Gardner's theory point to an important way to achieve this. In fact, the main practical implications of the present study are oriented to the consolidation of evidences for the design and development of healthy programs in higher education, which promote healthy lifestyles among young university students. Further research will be oriented to the development of longitudinal research, with larger samples where the relationship between the variables considered can be examined in more detail and the real impact of healthy education based on the theory of multiple intelligences for the university population can be known.

Author Contributions: Conceptualization, J.L.U.-J., F.Z.-O., and G.G.-V.; methodology, S.S.R.-M. and P.P.-M.; formal analysis, J.L.U.-J., F.Z.-O., S.S.R.-M., and G.G.-V.; writing-original draft preparation, J.L.U.-J., F.Z.-O., G.G.-V., P.P.-M., and S.S.R.-M.; writing-review and editing, J.L.U.-J., F.Z.-O., G.G.-V., P.P.-M., and S.S.R.-M.; supervision, J.L.U.-J. and F.Z.-O. All authors have read and agreed to the published version of the manuscript.

Funding: This research was funded by Spanish Ministry of Education, grant number FPU16/03114.

Conflicts of Interest: The authors declare no conflict of interest.

\section{References}

1. De-Mateo-Silleras, B.; Camina-Martin, M.A.; Cartujo-Redondo, A.; Carreño-Enciso, L.; de-la-Cruz-Marcos, S.; Redondo-del-Río, P. Health Perception According to the Lifestyle of University Students. J. Community Health 2019, 44, 74-80. [CrossRef] [PubMed]

2. Hauber, K.; Boon, A.; Kuipers, G.; Vermeiren, R. Adolescent attachment insecurity and the influence of MBT. Attach. Hum. Dev. 2020, 22, 157-173. [CrossRef] [PubMed]

3. Kovacs, K.; Conway, A.R. A Unified Cognitive/Differential Approach to Human Intelligence: Implications for IQ Testing. J. Appl. Res. Mem. Cogni. 2019, 8, 255-272. [CrossRef] 
4. Statti, A.L.; Torres, K.M. Multiple Intelligence Theory in the Digital Age of Learning. In Examining Multiple Intelligences and Digital Technologies for Enhanced Learning Opportunities; IGI Global: Hershey, PA, USA, 2020; pp. 1-18.

5. García, T.; Fernández, E.; Vázquez, A.; García, P.; Rodríguez, C. Gender and perceived multiple intelligences. Analysis as a function of the informant. Psicol. Educ. 2018, 24, 31-37. [CrossRef]

6. Gardner, H. La Inteligencia Reformulada: Las Inteligencias Múltiples en el Siglo XXI; Paidós: Barcelona, Spain, 2010.

7. Bas, G. The effect of multiple intelligences theory-based education on academic achievement: A meta-analytic review. Educ. Sci. Theory Pract. 2016, 16, 1833-1864.

8. Grillone, L.; Castriotta, L.; Antinolfi, F.; Righini, M.; Brusaferro, S.; Parpinel, M. University students' Mediterranean diet adherence in North East of Italy: A pilot study, 2018. Eur. J. Public Health 2018, 28, 430. [CrossRef]

9. Furnham, A. Increasing your intelligence: Entity and incremental beliefs about the multiple "intelligences". Learn. Individ. Differ. 2014, 32, 163-167. [CrossRef]

10. Martínez-Lacoba, R.; Pardo-García, I.; Amo-Saus, E.; Escribano-Sotos, F. Social determinants of food group consumption based on Mediterranean diet pyramid: Across-sectional study of university students. PLoS ONE 2020, 15, e022762. [CrossRef]

11. Aidoud, A.; Ziane, E.; Vara, L.; Terron, M.P.; Garrido, M.; Rodríguez-Rodríguez, A.B.; Carrasco, C. Changes in Mediterranean dietary pattern of university students: A comparative study between Spain and Algeria. Nutr. Clínica Dietética Hosp. 2019, 39, 26-33. [CrossRef]

12. Antonopoulou, M.; Mantzorou, M.; Serdari, A.; Bonotis, K.; Vasios, G.; Pavlidou, E.; Trifonos, C.; Vadikolias, K.; Petridis, D.; Giaginis, C. Evaluating Mediterranean diet adherence in university student populations: Does this dietary pattern affect students' academic performance and mental health? Int. J. Health Plan. Manag. 2020, 35, 5-21. [CrossRef]

13. Muros, J.J.; Cofre-Bolados, C.; Arriscado, D.; Zurita, F.; Knox, E. Mediterranean diet adherence is associated with lifestyle, physical fitness, and mental wellness among 10-y-olds in Chile. Nutrition 2017, 35, 87-92. [CrossRef] [PubMed]

14. Arriscado, D.; Muros, J.J.; Zabala, M.; Dalmau, J.M. Factors associated with low adherence to a Mediterranean diet in healthy children in northern Spain. Appetite 2014, 80, 28-34. [CrossRef]

15. Borzì, A.M.; Biondi, A.; Basile, F.; Luca, S.; Vicari, E.S.D.; Vacante, M. Olive Oil Effects on Colorectal Cancer. Nutrients 2019, 11, 32. [CrossRef] [PubMed]

16. San Román-Mata, S.; Zurita-Ortega, F.; Martínez-Martínez, A.; Padial-Ruz, R.; Chacón-Cuberos, R.; Linares-Manrique, M. Adherencia a la Dieta Mediterránea en estudiantes universitarios del sur de España según factores sociales, académicos y religiosos. Rev. Española Nutr. Hum. Dietética 2018, 22, 141-148. [CrossRef]

17. González-Valero, G.; Ubago-Jiménez, J.L.; Ramírez-Granizo, I.A.; Puertas-Molero, P. Association between Motivational Climate, Adherence to Mediterranean Diet, and Levels of Physical Activity in Physical Education Students. Behav. Sci. 2019, 9, 37. [CrossRef]

18. De la Montaña, J.; Castro, L.; Cobas, N.; Rodríguez, M.; Mínguez, M. Adherencia a la dieta mediterránea y su relación con el índice de masa corporal en universitarios de Galicia. Nutr. Clínica Dietética Hosp. 2012, 32, 72-80.

19. Rodríguez, F.J.; Espinoza, L.R.; Gálvez, J.; Macmillan, N.G.; Solís, P. Estado nutricional y estilos de vida en estudiantes universitarios de la Pontificia Universidad Católica de Valparaíso. Univ. Salud 2013, 15, 123-135.

20. Radd-Vagenas, S.; Duffy, S.L.; Naismith, S.L.; Brew, B.J.; Flood, V.M.; Fiatarone Singh, M.A. Effect of the Mediterranean diet on cognition and brain morphology and function: A systematic review of randomized controlled trials. Am. J. Clin. Nutr. 2018, 107, 389-404. [CrossRef]

21. Wade, A.T.; Elias, M.F.; Murphy, K.J. Adherence to a Mediterranean diet is associated with cognitive function in an older non-Mediterranean sample: Findings from the Maine-Syracuse Longitudinal Study. Nutr. Neurosci. 2019, 1-12. [CrossRef]

22. Zamroziewicz, M.K.; Barbey, A.K. Chapter 2-The Mediterranean Diet and Healthy Brain Aging: Innovations from Nutritional Cognitive Neuroscience. In Role of the Mediterranean Diet in the Brain and Neurodegerative Diseases; Academic Press: Cambridge, MA, USA, 2018; pp. 17-33. 
23. Masana, M.F.; Koyanagi, A.; Haro, J.M.; Tyrovolas, S. n-3 Fatty acids, Mediterranean diet and cognitive function in normal aging: A systematic review. Exp. Gerontol. 2017, 91, 39-50. [CrossRef]

24. Godos, J.; Galvano, F. Insights on Mediterranean Diet from the SUN Cohort: Cardiovascular and Cognitive Health. Nutrients 2020, 12, 1332. [CrossRef] [PubMed]

25. Galbete, C.; Toledo, E.; Toledo, J.B.; Bes-Rastrollo, M.; Buil-Cosiales, P.; Marti, A.; Guillén-Grima, F.; Martínez-González, M.A. Mediterranean diet and cognitive function: The sun project. J. Nutr. Health Aging 2015, 19, 305-312. [CrossRef] [PubMed]

26. World Health Organization WHO. Global Recommendations on Physical Activity for Health. 2010. Available online: https://cutt.ly/YdMYylZ (accessed on 23 January 2020).

27. Liu, P.Z.; Nusslock, R. Exercise-Mediated Neurogenesis in the Hippocampus via BDNF. Front. Neurosci. 2018, 12, 52. [CrossRef] [PubMed]

28. Wilke, J. Functional high-intensity exercise is more effective in acutely increasing working memory than aerobic walking: An exploratory randomized, controlled trial. Sci. Rep. 2020, 10, 12335. [CrossRef]

29. Aparicio-Ugarriza, R.; Mielgo-Ayuso, J.; Ruiz, E.; Ávila, J.M.; Aranceta-Bartrina, J.; Gil, Á.; Ortega, R.M.; Serra-Majem, L.; Varela-Moreiras, G.; González-Gross, M. Active commuting, physical activity, and sedentary behaviors in children and adolescents from Spain: Findings from the ANIBES Study. Int. J. Environ. Res. Public Health 2020, 17, 668. [CrossRef]

30. Budde, H.; Voelcker-Rehage, C.; Pietrabyk-Kendziorra, S.; Ribeiro, P.; Tidow, G. Acute coordinative exercise improves attentional performance in adolescents. Neurosci. Lett. 2008, 441, 219-223. [CrossRef]

31. Norris, E.; van Steen, T.; Direito, A.; Stamatakis, E. Physically active lessons in schools and their impact on physical activity, educational, health and cognition outcomes: A systematic review and meta-analysis. Br. J. Sports Med. 2020, 54, 826-838. [CrossRef]

32. Gunnell, K.E.; Poitras, V.J.; LeBlanc, A.; Schibli, K.; Barbeau, K.; Hedayati, N.; Ponitfex, M.B.; Goldfield, G.S.; Dunlap, C.; Lehan, E.; et al. Physical activity and brain structure, brain function, and cognition inchildren and youth: A systematic review of randomized controlled trials. Ment. Health Phys. Act. 2019, 16, 105-127. [CrossRef]

33. Ramírez-Vélez, R.; Correa-Rodríguez, M.; Izquierdo, M.; Schmidt-RioValle, J.; González-Jiménez, E. Muscle fitness to visceral fat ratio, metabolic syndrome and ideal cardiovascular health metrics. Nutrients 2019, 11, 24. [CrossRef]

34. Cassilhas, R.C.; Lee, K.S.; Fernandes, J.; Oliveira, M.G.; Tufik, S.; Meeusen, R.; de Mello, M.T. Spatial memory is improved by aerobic and resistance exercise through divergent molecular mechanisms. Neuroscience 2012, 202, 309-317. [CrossRef]

35. Trivino-Paredes, J.; Patten, A.R.; Gil-Mohapel, J.; Christie, B.R. The effects of hormones and physical exercise on hippocampal structural plasticity. Front. Neuroendocrinol. 2016, 41, 23-43. [CrossRef]

36. Ten Brinke, L.F.; Bolandzadeh, N.; Nagamatsu, L.S.; Hsu, C.L.; Davis, J.C.; Miran-Khan, K.; Liu-Ambrose, T. Aerobic exercise increases hippocampal volume in older women with probable mild cognitive impairment: A 6-month randomised controlled trial. Br. J. Sports Med. 2015, 49, 248-254. [CrossRef] [PubMed]

37. Nagamatsu, L.S.; Handy, T.C.; Hsu, C.L.; Voss, M.; Liu-Ambrose, T. Resistance training promotes cognitive and functional brain plasticity in seniors with probable mild cognitive impairment. Arch. Intern. Med. 2012, 172, 666-668. [CrossRef]

38. Meincke, R.H.; Hansen, Å.M.; Mortensen, L.H.; Osler, M.; Mortensen, E.L. Intelligence in early adulthood and midlife physical performance in men: The mediating roles of education and physical activity. Intelligence 2016, 58, 62-68. [CrossRef]

39. Serrá-Majem, L.; Ribas, L.; Ngo, J.; Ortega, R.M.; García, A.; Pérez-Rodrigo, C.; Aranceta, J. Food, youth and the Mediterranean diet in Spain. Development of KIDMED, Mediterranean diet quality index in children and adolescents. Public Health Nutr. 2004, 7, 931-935.

40. McClellan, J.A.; Conti, G.J. Identifying the Multiple Intelligence of your students. J. Adult Educ. 2008, 37, 13-36.

41. Salcedo, J.A. Multiple intelligences and academic performance in university students in Huancayo, 2015. Apunt. Cienc. Soc. 2016, 6, 29-35. [CrossRef] 
42. Zaranza, L.; Ramirez, A.; Alves, N.; de Souza, P.; Oliveira, D.J.; Chagas, L.; Thiago, J.M. Behavioral health risk profiles of physical education undergraduates. Motriz 2019, 25, e10190146. [CrossRef]

43. Ekici, S. Multiple intelligence levels of physical education and sports school students. Educ. Res. Rev. 2011, 6, 1018-1026. [CrossRef]

44. Kivunja, C. Creative engagement of digital learners with Gardner's bodilykinesthetic intelligence to enhance their critical thinking. Creat. Educ. 2015, 6, 612-622. [CrossRef]

45. Meeusen, R. Exercise, Nutrition and the Brain. Sports Med. 2014, 44, 47-56. [CrossRef] [PubMed]

46. Chacón-Cuberos, R.; Zurita-Ortega, F.; Martínez-Martínez, A.; Olmedo-Moreno, E.M.; Castro-Sánchez, M. Adherence to the Mediterranean Diet Is Related to Healthy Habits, Learning Processes, and Academic Achievement in Adolescents: A Cross-Sectional Study. Nutrients 2018, 10, 1566. [CrossRef] [PubMed]

47. Trigueros, R.; Mínguez, L.A.; González-Bernal, J.J.; Jahouh, M.; Soto-Camara, R.; Aguilar-Parra, J.M. Influence of Teaching Style on Physical Education Adolescents' Motivation and Health-Related Lifestyle. Nutrients 2019, 11, 2594. [CrossRef]

48. López-Olivares, M.; Mohatar-Barba, M.; Fernández-Gómez, E.; Enrique-Mirón, C. Mediterranean Diet and the Emotional Well-Being of Students of the Campus of Melilla (University of Granada). Nutrients 2020, 12, 1826. [CrossRef] [PubMed]

49. Oh, S.H.; Sun, J.S.; Jang, S.H. A Study of the Relation Between Nursing Students' Global Competences and Their Multiple Intelligences for the Fourth Industrial Revolution. J. Converg. Inf. Technol. 2017, 7, 13-26. [CrossRef]

50. Furnham, A.; Shagabutdinova, K. Sex differences in estimating multiple intelligences in self and others: A replication in Russia. Int. J. Psychoanal. 2012, 47, 448-459. [CrossRef]

51. Jackson, D.B.; Beaver, K.M. The Role of Adolescent Nutrition and Physical Activity in the Prediction of Verbal Intelligence during Early Adulthood: A Genetically Informed Analysis of Twin Pairs. Int. J. Environ. Res. Public Health 2015, 12, 385-401. [CrossRef]

52. Grosso, G.; Biondi, A.; Galvano, F.; Mistretta, A.; Marventano, S.; Buscemi, S.; Drago, F.; Basile, F. Factors Associated with Colorectal Cancer in the Context of the Mediterranean Diet: A Case-Control Study. Nutr. Cancer 2014, 66, 558-565. [CrossRef]

53. Dernini, S.; Berry, E.; Serra-Majem, L.; La Vecchia, C.; Capone, R.; Medina, F.; Aranceta-Bartrina, J.; Belahsen, R.; Burlingame, B.; Calabrese, G.; et al. Med Diet 4.0: The Mediterranean diet with four sustainable benefits. Public Health Nutr. 2017, 20, 1322-1330. [CrossRef]

54. Corley, J.; Starr, J.M.; McNeill, G.; Deary, I.J. Do dietary patterns influence cognitive function in old age? Int. Psychogeriatr. 2013, 25, 1393-1407. [CrossRef]

55. Chacón-Cuberos, R.; Castro-Sánchez, M.; Muros-Molina, J.J.; Espejo-Garcés, T.; Zurita-Ortega, F.; Linares-Manrique, M. Adhesión a la dieta mediterránea en estudiantes universitarios y su relación con los hábitos de ocio digital. Nutr. Hosp. 2016, 33, 405-410. [CrossRef] [PubMed]

56. Chan, D.W. Perceived Multiple Intelligences Among Male and Female Chinese Gifted Students in Hong Kong: The Structure of the student Multiple Intelligence profile. Gift. Child Q. 2006, 50, 325-356. [CrossRef]

57. Ermis, E.; Imamoglu, O. The effect of doing sports on the multiple intelligences of university students. Int. J. Acad. Res. 2013, 5, 174-179. [CrossRef]

58. Lopes, P.; Mestre, J.; Guil, R.; Pickard, J.; Salovey, P. The Role of Knowledge and Skills for Managing Emotions in Adaptation to School: Social Behavior and Misconduct in the Classroom. Am. Educ. Res. J. 2012, 49, 710-742. [CrossRef]

59. Yazici, H.; Seyis, S.; Altun, F. Emotional intelligence and self-efficacy beliefs as predictors of academic achievement among high school students. Procedia Soc. Behav. Sci. 2011, 15, 2319-2323. [CrossRef]

60. de Looze, M.; Elgar, F.J.; Currie, C.; Kolip, P.; Stevens, G.W.J.M. Gender Inequality and Sex Differences in Physical Fighting, Physical Activity, and Injury Among Adolescents Across 36 Countries. J. Adolesc. Health 2019, 64, 657-663. [CrossRef]

61. Wilson, O.W.A.; Papalia, Z.; Duffey, M.; Bopp, M. Differences in college students' aerobic physical activity and muscle-strengthening activities based on gender, race, and sexual orientation. Prev. Med. Rep. 2019, 100984. [CrossRef] 
62. Saeed Ghorbani, S.; Noohpisheh, S.; Shakki, M. Gender Differences in the Relationship between Perceived Competence and Physical Activity in Middle School Students: Mediating Role of Enjoyment. Int. J. School Health 2020, 7, 14-20. [CrossRef]

63. Panadero-Pérez, N.; Ruiz-San Román, B.M.; Joya-Barroso, M.; San Román-Mata, S. Digital sedentarism as a precursor to the deterioration of health adolescents and young people. ESHPA 2019, 3, 368-383.

(C) 2020 by the authors. Licensee MDPI, Basel, Switzerland. This article is an open access article distributed under the terms and conditions of the Creative Commons Attribution (CC BY) license (http://creativecommons.org/licenses/by/4.0/). 